RHINOLOGY

\title{
Cyclamen europaeum improves the effect of oral antibiotics on exacerbations and recurrences of chronic rhinosinusitis: a real-life observational study (CHRONOS)
}

\author{
L'estratto di Cyclamen europaeum per via intranasale implementa l'effetto degli \\ antibiotici orali nel trattamento delle riacutizzazioni delle rinosinusiti croniche: \\ studio osservazionale in vivo (CHRONOS)
}

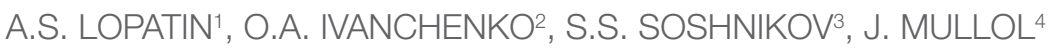 \\ ${ }^{1}$ Policlinic N. 1, Medical Department, Business Administration of the President of the Russian Federation, Moscow, \\ Russia; ${ }^{2}$ Consultative and Diagnostic Policlinic N. 121, Moscow Healthcare Department, Moscow, Russia; \\ 3Department of Mathematical Modelling in Medicine, Central Research Institute for Public Health, Ministry of \\ Healthcare of the Russian Federation, Moscow, Russia; ${ }^{4}$ Rhinology Unit and Smell Clinic, ENT Department, Hospital \\ Clínic \& Clinical and Experimental Respiratory Immunoallergy, IDIBAPS\& CIBERES. Barcelona, Catalonia, Spain
}

\section{SUMMARY}

Chronic rhinosinusitis (CRS) is an inflammatory disease of the nose and paranasal sinuses affecting $11 \%$ of the European population. $C y$ clamen europaeum plant extract $(C E)$ has demonstrated efficacy in treating acute rhinosinusitis, but its role in CRS exacerbations remains unknown. In this real-life, prospective, epidemiological, observational study, a total of 317 patients with exacerbations of CRS without nasal polyps (CRSsNP) of moderate severity were treated using three different options: oral antibiotics, $C E$ extract nasal spray, or the combination of oral antibiotic with $C E$ extract. The main outcomes were the effect of treatment on sinonasal symptoms and endoscopic appearance after 6 weeks of therapy, and the number of recurrences of CRS exacerbations after 6 months of follow-up. On the top of oral antibiotics, $C E$ extract significantly improved sinonasal symptoms and endoscopic findings and caused a 4-fold reduction of CRS recurrences. When administered in monotherapy, $C E$ extract was at least as effective as antibiotic in monotherapy on relief of both symptoms and reduction of CRS recurrences. In patients with CRS exacerbation of moderate severity, $C E$ extract nasal spray in monotherapy or added to standard antibiotic treatment significantly reduces sinonasal symptoms and CRS recurrences compared to antibiotics in monotherapy.

KEY WORDS: Antibiotics • Chronic rhinosinusitis $\bullet$ Cyclamen europaeum $\bullet$ Nasal endoscopic score $\bullet$ Observational study $\bullet$ Real life $•$ Symptom score

\section{RIASSUNTO}

La rinosinusite cronica (CRS) è una malattia infiammatoria delle cavità naso-sinusali che colpisce l'11\% della popolazione europea. L'estratto vegetale di Cyclamen europaeum (CE) ha dimostrato efficacia nel trattamento della rinosinusite acuta, ma il suo ruolo nelle riacutizzazioni della CRS rimane sconosciuto. Il presente studio prospettico osservazionale epidemiologico in vivo ha coinvolto 317 pazienti con riacutizzazioni della CRS senza polipi nasali (CRSSNP) di moderata gravità trattati con tre diverse opzioni terapeutiche: antibiotici per os, spray nasale contenente estratto di CE, o la combinazione di antibiotici per via orale con estratto di CE. L'efficacia è stata valutata in base all'efficacia del trattamento sui sintomi sinusali, all'aspetto endoscopico dopo 6 settimane di terapia, al numero di recidive di esacerbazione di CRS con un follow-up di 6 mesi. In combinazione con la terapia antibiotica orale, l'estratto di CE ha migliorato significativamente $i$ sintomi sinusali, $i$ reperti endoscopici ed ha ridotto di 4 volte le recidive di CRS. Quando amministrato come monoterapia l'estratto di CE si è dimostrato almeno altrettanto efficace dell'antibiotico somministrato singolarmente sia riguardo al miglioramento dei sintomi che riguardo alla riduzione delle recidive CRS. Conclusioni: nei pazienti con riacutizzazione di CRS di moderata gravità, lo spray nasale a base di estratto di CE in monoterapia o in aggiunta al trattamento antibiotico standard riduce in modo significativo i sintomi sinusali e le ricorrenze di CRS rispetto agli antibiotici singolarmente somministrati.

PAROLE CHIAVE: Terapia antibiotica $\bullet$ Rinosinusiti croniche $\bullet$ Cyclamen europaeum

Acta Otorhinolaryngol Ital 2018;38:115-123 


\section{Introduction}

In recent decades, an increase in the prevalence of respiratory diseases, particularly inflammatory diseases of the nose and paranasal sinuses, has been observed ${ }^{1-3}$. Chronic rhinosinusitis (CRS) is a complex condition that dramatically affects the patient's quality of life and has profound effects on health care expenditure ${ }^{4-6}$. Management of this disease continues to challenge both patients and physicians. According to the European Position Paper on Rhinosinusitis and Nasal Polyp ( $\left.\mathrm{EP}_{3} \mathrm{OS} 2012\right)^{7}$, the prevalence of CRS is increasing annually, currently being one of the most common chronic diseases. For instance, the prevalence of CRS is $3.4 \%$ among Canadian men and $5.7 \%$ among women ${ }^{8}, 6 \%$ in Belgium ${ }^{9}$ and reaching $9.6 \%$ in the Scottish population ${ }^{10}$. CRS has been reported as high as $10.9 \%$ in Europe ${ }^{11}$ and $14 \%$ in the USA ${ }^{12}$.

An exact definition of an acute exacerbation of CRS (AE$\mathrm{CR}$ ) is not available. Usually this condition is defined as a sudden worsening of baseline symptoms (or developing new symptoms) in a patient with an established CRS diagnosis. Triggers leading to CRS disease exacerbation are also not well characterised. Previous epidemiologic studies have focused on identification of risk factors for a diagnosis of CRS rather than on risk factors that lead to disease exacerbation. Empirical definition criteria that were used for AECR are at least one of the following: a prescription for systemic antibiotics, systemic corticosteroids, plans for a semi-urgent surgical intervention, emergency department or urgent care visit, or hospitalisation ${ }^{13}$. Patients are approximately twice as likely to present with AECR in winter season when viral infections are known to be prevalent compared with spring, summer, or fall. Age and sex does not significantly affect the seasonal pattern ${ }^{13}{ }^{14}$. According to the $\mathrm{EP}_{3} \mathrm{OS}$ document, $\mathrm{AE}$ $\mathrm{CR}$ should be treated as acute rhinosinusitis (ARS), i.e. with intranasal corticosteroids and antibiotics, depending on symptom severity ${ }^{7}$.

There is good evidence supporting the concept that inflammation, more than infection, is the dominant aetiologic factor in CRS. Unlike ARS, pathogenic microorganisms play a much smaller role in the pathogenesis of CRS ${ }^{15}{ }^{17}$. However, based on the available evidence, oral antibacterial antibiotics (mainly in acute exacerbations) and prolonged macrolide antibiotics are considered therapeutic options in the treatment of CRS ${ }^{18}$. Although necessary to control AECR, both so-called "short" and "long-term" courses of antibiotic therapy may interfere with diversity and abundance of the paranasal sinuses microbial community and carry a risk of aggravation of dysbiosis that already exists in chronic inflammatory respiratory diseases like CRS ${ }^{19} 20$.
The ineffectiveness of the standard antibiotic therapy and the increased number of resistant strains of causative pathogens ${ }^{21} 22$, coupled with some doubts on the efficacy of corticosteroids in CRS without nasal polyps ${ }^{23}$ and the inability to achieve a total control with surgery ${ }^{24}$, indicate the need to develop new topical therapeutic modalities.

Cyclamen europaeum plant extract (CE) has been used since ancient times as a topical remedy, is devoid of undesirable systemic side effects and in general, is safer than systemically administered drugs. Like other topical remedies, $C E$ might offer a reliable alternative to conventional therapeutic approaches. Sinuforte ${ }^{\circledR}$ is the extract of the fresh tubers of Cyclamen europaeum that belongs to the Primulaceae family. This extract comes from a botanical raw material, a natural extract with many compounds, the active substances being saponins. Tubers of Cyclamen europaeum are lyophilised, without adding any excipient, to obtain $50 \mathrm{mg}$ of the lyophilised extract. A solvent (5 $\mathrm{ml}$ of water for injection) is provided for reconstitution of the lyophilised powder. Sinuforte ${ }^{\circledR}$ is administered to each nostril (2.6 mg once daily) for 8 days. Recent studies have confirmed the efficacy of $C E$ in treating ARS ${ }^{25}{ }^{26}$ but its role in AECR is still not known.

The objective of this study was to evaluate efficacy of $C E$ extract in treatment of AECR either as a monotherapy or in combination with an oral antibiotic and to compare its efficacy with standard oral antibiotic therapy.

\section{Materials and methods}

\section{Study population}

From June 2011 to February 2012, we conducted a real-life, prospective, observational study aimed to examine the efficacy of three different medical treatment protocols in patients with AECR without polyps. The study was conducted at 16 clinical centres across the Russian Federation. The study protocol was approved by the Inter-institutional Ethics Committee of the Sechenov First Moscow State Medical University. All the patients signed written informed consent before entering the study. A total of 327 patients aged 18 to 60 years and diagnosed with acute exacerbation of CRSsNP of moderate severity were enrolled. According to $\mathrm{EP}_{3} \mathrm{OS}$ 2012 criteria $^{7}$, a diagnosis of CRS was supported by clinical history, nasal endoscopy and computed tomography (CT) or plain X-rays of the paranasal sinuses.

\section{Inclusion criteria}

To be enrolled in the study, patients had to fulfill the following criteria:

established diagnosis of CRS (code J32.0-4 and J.32.8-9 
according to ICD-10 Version:2010), significant acute aggravation of symptoms (or development of new sinusitis symptom/symptoms) in the last 10 days that forced the patient to see an ENT physician, presence of two or more CRS symptoms and total Visual Analogue Scale (VAS) score of $>3-7$ at the time of entering the study, physician's decision for the need of specific therapy or escalation of the previous management.

Exclusion criteria included patients with CRS with nasal polyps, mild or severe CRSsNP according to VAS, absence of paranasal sinuses opacification on CT scans/ plain X-rays, orbital or intracranial complications, the use of systemic or topical antibiotics or corticosteroid therapy during the previous month, severe intercurrent illnesses (immunocompetent diseases, severe endocrine, respiratory or metabolic diseases, etc.) and pregnancy. Patients with concomitant allergic rhinitis were also excluded.

Patients with mild AECR were not included because they did not need antibiotic therapy. Patients with severe forms of AECR (in whom systemic antibiotics were necessary to prevent complications and monotherapy with $C E$ would not be sufficient) were likewise not included.

Ten patients were withdrawn at different stages of the study because they were unable to attend the next visit due to personal reasons; no patient withdrew from the study due to adverse effects or lack of treatment efficacy. Therefore, 317 patients completed the study and were suitable for statistical analysis.

\section{Study design}

Physicians in all centres had free choice to include patients in one of the three treatment protocols: patients in group 1 were treated with an oral antibiotic plus intranasal $C E$ (Sinuforte ${ }^{\circledR}$ Nasal Spray, Hartington Pharmaceutical, Barcelona, Spain), group 2 with intranasal $C E$ in monotherapy and group 3 with oral antibiotic alone. There were no strict recommendations for empirical antibiotic therapy, and participating physicians selected a first-line oral antibiotic according to their personal clinical experience and institutional guidelines. When used, $C E$ was administered to each nostril (2.6 mg once daily) for 8 days. Patients were free to stop the prescribed therapy and to discontinue their participation in the study at any time.

After start of the treatment, all patients were followed-up for 6 months by regular examination by the responsible observer. Patients from Groups 1 and 3 received systemic antibacterial therapy and the physicians' choice and dosages completely followed standards of empirical antibiotic therapy presented in rhinosinusitis national guidelines. The most common antibiotics prescribed were amoxicillin (1.0, 3 times daily) and amoxicillin/clavulanate (1.0, 2 times daily) followed by macrolides (clarithromycin $0.25,2$ times daily) and cephalosporins of the I-III generation. Routine antibiotic treatment was for 7 days (according to national guidelines) with some exclusions (for instance, azithromycin 0.5 once daily for 3 days, and moxifloxacin 0.4 once daily for 5 to 6 days). Physicians were encouraged to change the treatment protocol and to prescribe or change antibiotic when necessary. They were also free to use additional treatment options such as systemic or topical corticosteroids, topical antimicrobials, antral tap, sinus lavage, or Proetz replacement irrigations. Any change in the treatment protocol, use of additional therapeutic options and withdrawals were registered in case report forms. After the inclusion visit $\left(\mathrm{T}_{0}\right)$, patients were visited at day $3\left(\mathrm{~T}_{1}\right)$, day $5\left(\mathrm{~T}_{2}\right)$, and day 8/end of treatment $\left(\mathrm{T}_{3}\right)$ and after 6 weeks $\left(\mathrm{T}_{4}\right)$ of follow-up. After 6 months $\left(\mathrm{T}_{5}\right)$, patients were interviewed by a telephone call and asked about the number of episodes of AECR after discontinuation of treatment (Table I).

\section{Outcomes}

1. Nasal symptoms. Treatment efficacy was assessed at visits $\mathrm{T}_{1}-\mathrm{T}_{4}$. Assessment was based on the patient's subjective evaluation of the severity of the four main CRS symptoms (nasal obstruction, nasal discharge, facial pain/pressure, loss of smell or hyposmia) by VAS, $(10 \mathrm{~cm})$ as well as the composite evaluation of total nasal symptoms score (TNSS).

2. Nasal endoscopic assessment. Treatment efficacy was assessed at visits $\mathrm{T}_{1}-\mathrm{T}_{4}$. Semi-quantitative scores were recorded for middle meatal discharge and mucosal oedema. These results were evaluated using an endoscopic appearance score (EAS) ${ }^{27} 28$. Discharge was scored after decongestion as follows: 0 , no discharge; 1 , moderate amount of mucous or purulent discharge; and 2, large amount of thick, purulent discharge. $\mathrm{Mu}-$ cosal oedema was scored before decongestion as follows: 0 , absent; 1 , moderate, and 2 , severe.

3. Patient's self-perception of treatment efficacy was assessed at visits $\mathrm{T}_{3}$ and $\mathrm{T}_{4}$. The patient's assessment was scored as excellent, good, well/moderate, no effect, or bad/worsening.

\section{Statistical analysis}

With the help of a medical statistician (SSS), the results were entered into a computerised database and processed using the statistical software package SPSS version 17.0 for Windows. For each group of patients, the data distribution was identified, the frequency and scores were described and $95 \%$ confidence intervals were defined. Median, mode, standard error of the mean and standard deviation of the average, the minimum and maximum (variability), the in- 
Table I. Procedures performed during visits over the study duration.

\begin{tabular}{|c|c|c|c|c|c|c|}
\hline \multirow[b]{2}{*}{ Procedures } & \multicolumn{6}{|c|}{ Days/Visits } \\
\hline & $\begin{array}{l}\text { Day } 1 \\
\text { Visit } 0\end{array}$ & $\begin{array}{l}\text { Day } 3 \\
\text { Visit } 1\end{array}$ & $\begin{array}{l}\text { Day } 5 \\
\text { Visit } 2\end{array}$ & $\begin{array}{l}\text { Day } 8 \\
\text { Visit } 3\end{array}$ & $\begin{array}{c}6 \text { weeks } \\
\text { Visit 4: } \\
\text { Primary endpoint }\end{array}$ & $\begin{array}{l}6 \text { months } \\
\text { End of follow-up: } \\
\text { Secondary endpoint }\end{array}$ \\
\hline Sign informed consent & $x$ & - & - & - & - & - \\
\hline $\begin{array}{l}\text { Filling CRF, collecting medical history: concomitant } \\
\text { diseases, inclusion/exclusion criteria, previous therapies }\end{array}$ & $x$ & - & - & - & - & - \\
\hline Evaluation of symptoms severity (VAS) & $x$ & $x$ & $x$ & $x$ & $x$ & - \\
\hline General ENT examination & $x$ & $x$ & $x$ & $x$ & $x$ & - \\
\hline CT/plain X-rays of paranasal sinuses & $x$ & - & - & - & - & - \\
\hline Nasal endoscopy & $x$ & $x$ & $x$ & $x$ & $x$ & - \\
\hline Selecting treatment protocol & $x$ & - & - & - & - & - \\
\hline Checking patient adherence & - & $x$ & $x$ & $x$ & - & - \\
\hline Adverse events registration & - & $x$ & $x$ & $x$ & - & - \\
\hline Evaluation of treatment efficacy & - & $x$ & $x$ & $x$ & $x$ & - \\
\hline Telephone interview & - & - & - & - & - & $x$ \\
\hline
\end{tabular}

terquartile range values, ANOVA analysis of variance (Levene Statistic) and ANCOVA analysis of covariance across treatment groups and Wilcoxon signed-rank test were used to compare variables between the groups to determine statistical significance at various time points. Values were presented as mean \pm standard deviation (SD). Changes within and between the groups were considered statistically significant when $\mathrm{p}$ values were $<0.05$.

\section{Results}

A total of 317 patients with AECR (135 men and 182 women) aged from 18 to 60 years (mean $46.4 \pm 5.0$ ) were included in the study: $C E$ plus antibiotic (group 1, $\mathrm{N}=128$ ), $C E$ in monotherapy (group $2, \mathrm{~N}=90$ ) and antibiotic in monotherapy (group $3, \mathrm{~N}=99$ ). Baseline characteristics of patients are presented in Table II.

\section{Assessment of symptoms}

Total Nasal Symptom Score (TNSS). At baseline $\left(\mathrm{T}_{0}\right)$, TNSS was higher in group 1 than in group $2(\mathrm{p}<0.01)$. Starting from day $3\left(\mathrm{~T}_{1}\right)$ and at all consecutive time points, either oral antibiotic plus $C E$ or $C E$ in monotherapy induced a significantly $(\mathrm{p}<0.001)$ higher resolution of TNSS compared to oral antibiotic alone. After 6 weeks $\left(\mathrm{T}_{4}\right)$ of treatment initiation, TNSS was significantly reduced from $8.80 \pm 0.29$ at baseline to $0.78 \pm 0.16$ by antibiotic plus $C E$, from $7.93 \pm 0.25$ to $0.76 \pm 0.12$ by $C E$ alone and from $8.23 \pm 0.34$ to $1.70 \pm 0.22$ by antibiotic alone) (Fig. 1).

Individual Nasal Symptom Score. At baseline $\left(\mathrm{T}_{0}\right)$, scores for nasal congestion, facial pain/pressure and hyposmia were similar in all treatment groups, while score for na- sal discharge in group 1 was higher than in groups 2 and 3 ( $\mathrm{p}=0.001$ ). Either oral antibiotic plus $C E$ or $C E$ in monotherapy induced a significantly $(\mathrm{p}<0.001)$ higher resolution of nasal congestion and nasal discharge from day $5\left(\mathrm{~T}_{2}\right)$ to week $6\left(\mathrm{~T}_{4}\right)$ and from day $8\left(\mathrm{~T}_{3}\right)$ to week 6 $\left(\mathrm{T}_{4}\right)$ than antibiotics in monotherapy (Fig. $2 \mathrm{a}-\mathrm{d}$ ). All three treatment options improved hyposmia during the treatment period but with no significant differences between the groups. No significant difference was found between oral antibiotic plus $C E$ and $C E$ in monotherapy for all individual symptom improvements.

Nasal endoscopy assessment. At baseline $\left(\mathrm{T}_{0}\right)$, EAS for middle meatus discharge, but not for oedema, was significantly $(\mathrm{p}<0.01)$ worse in group 1 than in groups 2 and

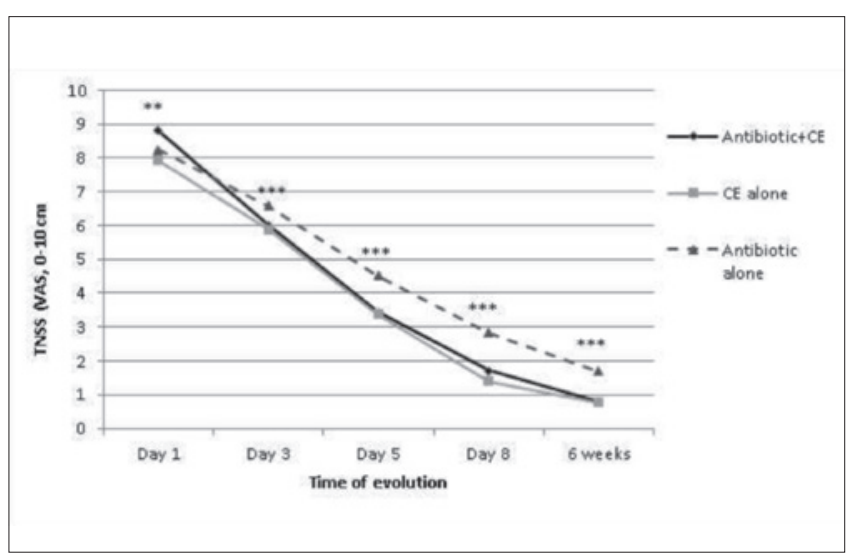

Fig. 1. Evolution of Total Nasal Symptom score (VAS) during AECR treatment. Comparison between groups $\left({ }^{\star \star}, p<0.01\right.$; ${ }^{\star \star \star}, p<0.001$, between groups). 
Table II. Baseline characteristics of patients receiving the three treatment protocols.

\begin{tabular}{lcccc} 
& $\begin{array}{c}\text { Group 1 } \\
\text { (antibiotic + CE) }\end{array}$ & $\begin{array}{c}\text { Group 2 } \\
\text { (CE in monotherapy) }\end{array}$ & $\begin{array}{c}\text { Group 3 } \\
\text { (antibiotic in } \\
\text { monotherapy) }\end{array}$ & $\begin{array}{c}\text { All } \\
\text { patients }\end{array}$ \\
Patients, N (\%) & $128(40.3 \%)$ & $90(28.4 \%)$ & $99(31.3 \%)$ & $317(100 \%)$ \\
Gender (female), N (\%) & $74(57.8 \%)$ & $53(58.9 \%)$ & $55(55.6 \%)$ & $182(57.4 \%)$ \\
Age, years (mean \pm SD) & $49.7 \pm 4.7$ & $47.3 \pm 5.3$ & $42.3 \pm 4.9$ & $46.4 \pm 5.0$ \\
TNSS, VAS (mean \pm SD) & $8.80 \pm 0.29^{\star}$ & $7.93 \pm 0.25$ & $8.23 \pm 0.34$ & $8.32 \pm 0.29$ \\
EAS, middle meatus discharge (mean $\pm S D)$ & $2.35 \pm 0.09$ & $2.07 \pm 0.10$ & $2.11 \pm 0.12$ & $2,18 \pm 0.1$ \\
EAS, middle meatus mucosal edema (mean $\pm S D)$ & $2.55 \pm 0.07$ & $2.49 \pm 0.08$ & $2.59 \pm 0.11$ & $2.54 \pm 0.09$ \\
\hline
\end{tabular}

CE, Cyclamen europaeum; TNSS, Total Nasal Symptom Score; EAS, Endoscopic Assessment Score; SD, standard deviation; VAS, Visual Analogue Score; *,$p<0.01$ vs. group 2.

3. Either oral antibiotic plus $C E$ or $C E$ in monotherapy induced a significant $(\mathrm{p}<0.001)$ reduction of the middle meatus mucosal oedema from day $3\left(\mathrm{~T}_{1}\right)$ to week $6\left(\mathrm{~T}_{4}\right)$ (Fig. 3). Regarding the score for middle meatus discharge, there was no significant difference between groups at $\mathrm{T}_{1}$ $\mathrm{T}_{3}$ visits, however, at visit $\mathrm{T} 4$ the score in group 3 (oral antibiotic alone) was significantly $(\mathrm{p}<0.05)$ higher than in group 2 ( $C E$ alone). No statistical difference was found between groups 1 and 2 at $\mathrm{T}_{1}-\mathrm{T}_{4}$ visits.

Patient self-evaluation of treatment efficacy. After 8 days of active treatment $\left(\mathrm{T}_{3}\right)$, no patient in any group reported that they feel "worse/bad"; an absence of effect was revealed more frequently in group 3 (oral antibiotic alone) and least in group $2(C E)(\mathrm{p}=0.013)$. The number of "well/moderate" assessments was not significantly different between the three groups; "good effect" assessment in group 3 (oral antibiotic alone) was three times less frequent than in group 1 (oral antibiotic $+C E$ ) and group 2 (CE alone) $(\mathrm{p}=0.001)$; the same number of "excellent" results according to patient assessment was recorded in all groups (Fig. 4a). Six weeks after $\left(\mathrm{T}_{4}\right)$, a "bad effect" was reported by a few patients in groups 2 and 3; "no effect" and "well/moderate" was observed in the same number of patients; a "good" effect was more often reported in group 1 than in group $2(\mathrm{p}=0.023)$ and six times less frequently in group 3 ( $p=0.007$ ) (Fig. $4 b)$.

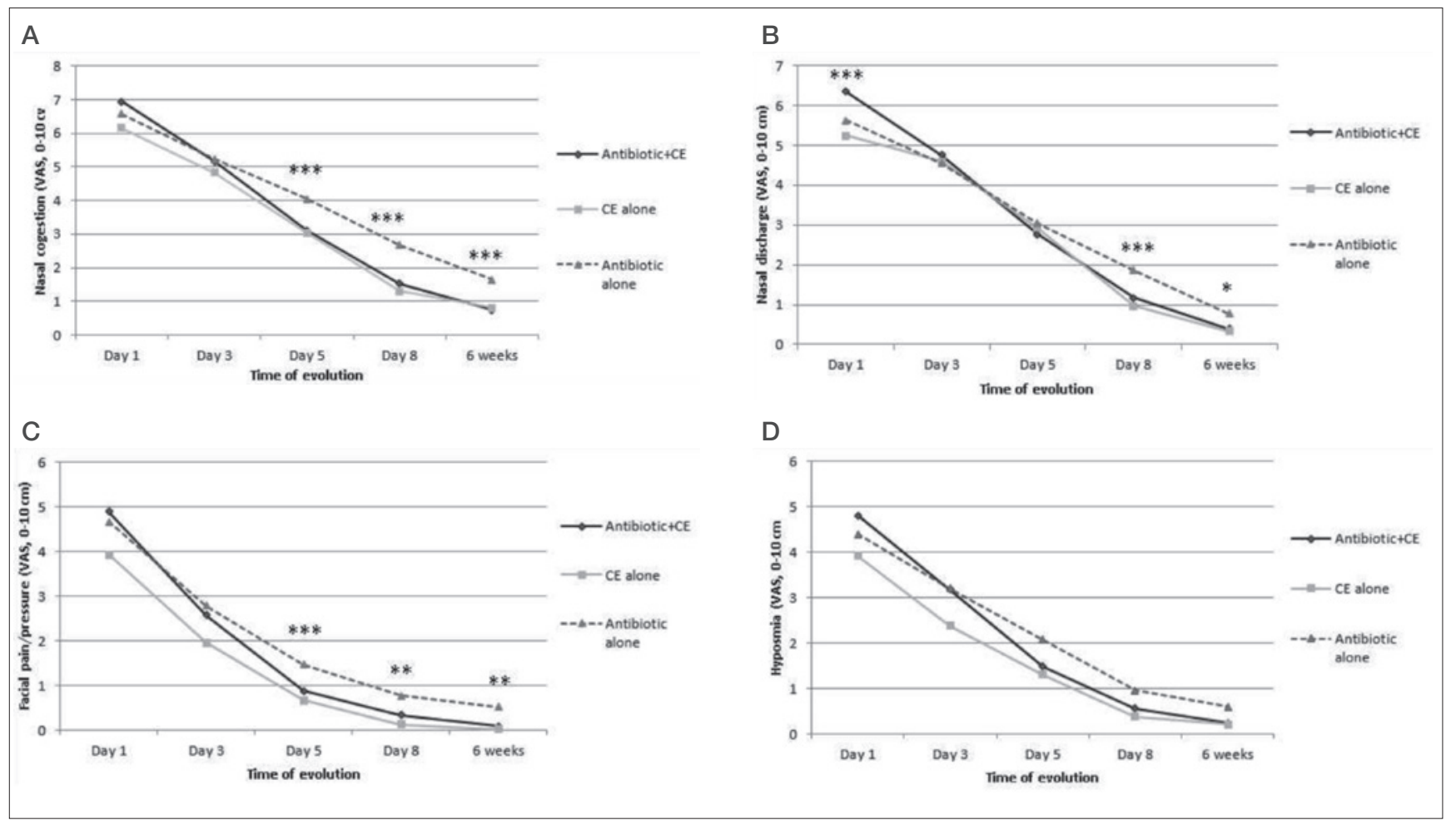

Fig. 2. Evolution of individual symptoms (VAS) during AECR treatment. Nasal congestion (A), nasal discharge (B), facial pain/pressure (C) and loss of smell/ hyposmia (D). Comparison between groups ( $\left.{ }^{*}, p<0.05 ;{ }^{* \star}, p<0.01 ;{ }^{* \star}, p<0.001\right)$. 


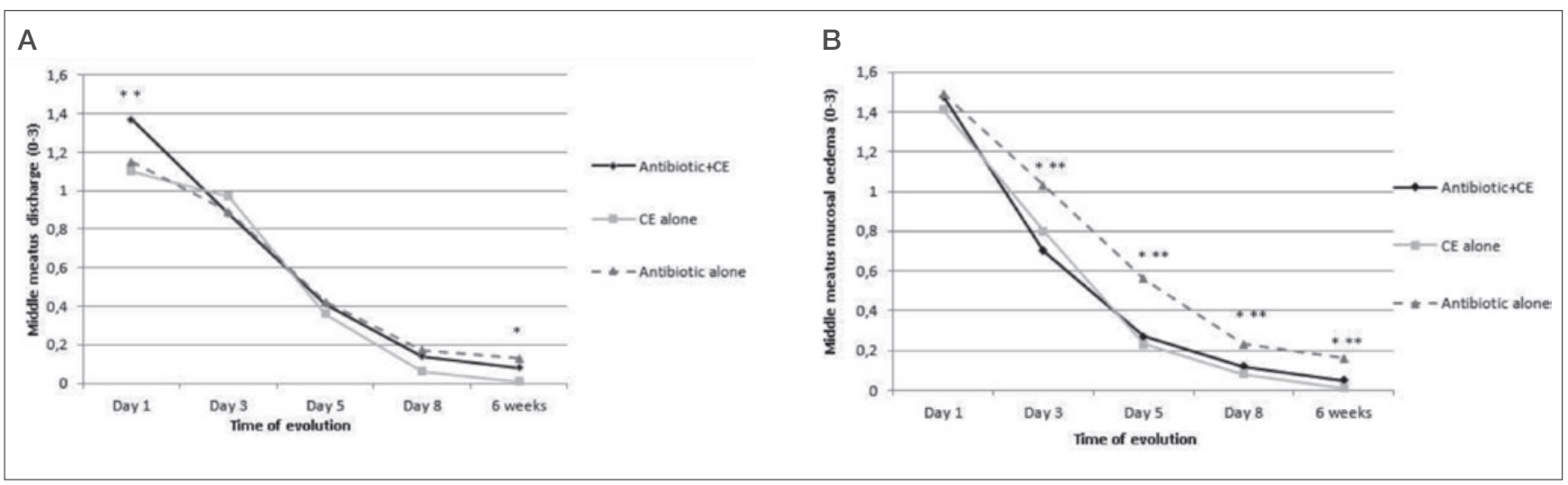

Fig. 3. Evolution of endoscopic appearance score (EAS) during AECR treatment. Middle meatus discharge (A) and mucosal oedema (B). Comparison between groups ( $\left.{ }^{*}, p<0.05 ;{ }^{* \star}, p<0.01 ;{ }^{* \star}, p<0.001\right)$.

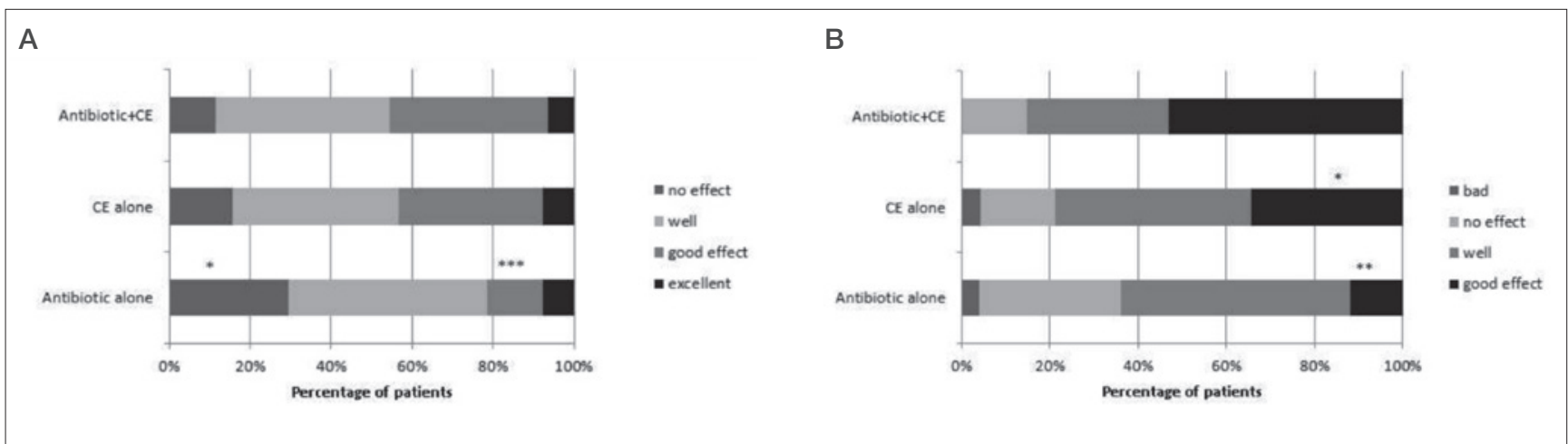

Fig. 4. Patients' self-perception of treatment efficacy: (A) after discontinuation of therapy $\left(T 3,8\right.$ days) $\left({ }^{*}, p<0.01\right.$ compared to group 1 ; ${ }^{\star \star *}, p<0.01$ vs. group 1). (B) short-term follow-up (T4, 6 weeks). ( ${ }^{\star}, p<0.01$ vs. group $1 ;{ }^{* \star}, p<0.01$ vs. group 1).

\section{Recurrence rate assessment}

When interviewed by telephone 6 months $\left(\mathrm{T}_{5}\right)$ after the start of the therapy, patients treated with antibiotic and $C E$ reported significantly less $(\mathrm{p}<0.01)$ AECR than those treated with either $C E$ or antibiotic in monotherapy (Fig. 5). Only 3.9\% ( $\mathrm{N}=5)$ of patients treated with antibiotic plus $C E$ reported exacerbations (4 patients with one episode and 1 patient with two episodes) compared to $23.3 \%(\mathrm{~N}=21)$ of patients treated with $C E$ alone (14 patients with one episode and 7 patients with two episodes) or $20.2 \%(\mathrm{~N}=20)$ of patients treated with antibiotic alone (14 patients with one episode, 3 patients with 2 episodes, 2 patients with 3 episodes and 1 patient with 4 episodes).

\section{Changes to therapeutic protocols}

In group 1, the selected antibiotic was not replaced in any patient. In group 2, $C E$ was supplemented with an antibiotic in $5.5 \%$ of patients. In group 3, the selected antibiotic was replaced due to lack of clinical efficacy with a

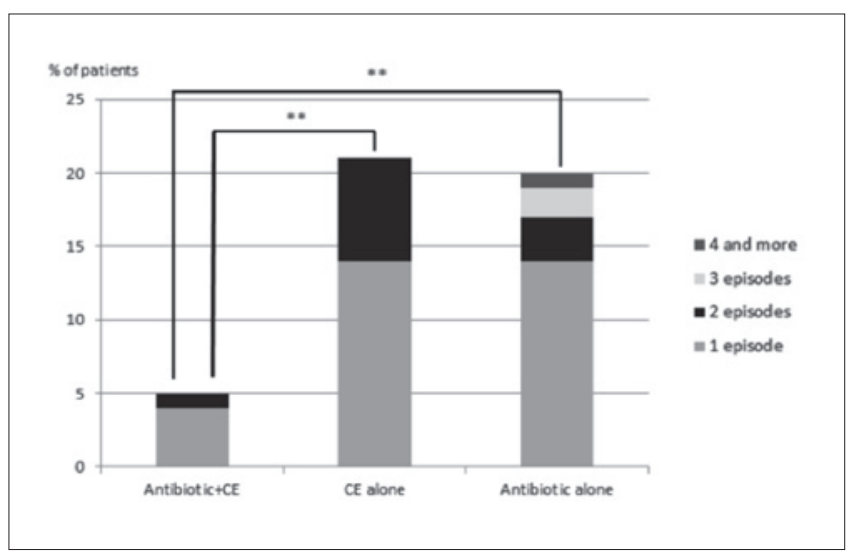

Fig. 5. Number of AECR during 6-month follow-up. Comparison between treatment.

second-line antibiotic in 5\% of patients. In no case were systemic or topical corticosteroids added to initial therapy in any study group. Antral puncture and sinus lavage, as 
adjunct to initial therapy, was performed after 3 or 5 days of therapy in $3.1 \%$ and $13.1 \%$ of patients from group 1 and group 3, respectively, but in no patients in group 2 . Proetz nasal lavage, as adjunct to initial therapy, was conducted after 3 or 5 days in $2.3 \%$ of patients from group 1 , $4.4 \%$ of patients from group 2 and $9.1 \%$ of patients from group 3. Therefore, in terms of the need for alternative therapeutic options, physician satisfaction with treatment efficacy was significantly $(\mathrm{p}<0.05)$ higher in groups 1 and 2 (both with $C E$ extract) than in group 3.

Adverse events. No severe adverse events were reported in this study. Only 7 patients (5 in group 1 and 2 in group 2) reported mild adverse effects (itching, sneezing, burning of the nose or throat irritation) after $C E$ extract nasal spray, which did not require changes in the protocol or study withdrawal.

\section{Discussion}

While systemic antibiotics (for severe bacterial disease) and intranasal corticosteroids (for moderate to severe disease) remain a mainstay in treatment of ARS and AECR, several studies have been carried out in recent years to find alternative therapies to improve the symptoms and severity of rhinosinusitis. In particular, two randomised controlled studies assessed the efficacy of herbal compounds in treatment of ARS. One study showed that Pelargonium sidoides might be effective in alleviating symptoms of ARS in adults ${ }^{29}$. The other randomised multicentre study assessed the efficacy of Myrtol in the treatment of ARS. The results showed a statistically significant difference in improvement of TNSS between active treatment and placebo. The need for antibiotic therapy after Myrtol was 23\%, compared to $40 \%$ for placebo ${ }^{30}$.

The tuber of Cyclamen europaeum (Cyclamen purpurascens), a member of the Primulaceae family, has been used in herbal medicine since ancient times as a topical remedy for a range of indications. An extract of the tuber has been used for sinusitis in the form of nasal spray. The chemical composition of $C E$ has not been thoroughly studied. The most examined active components of $C E$ are triterpenoid saponins that belong to the group of organic glycosides. The saponin fraction of CE stimulates nasoparanasal secretions. When delivered to the nasal cavity, $C E$ with its saponin fraction causes irritation of the trigeminal nerve endings in the nasal mucosa through cholinergic pathways, leading to rapid and abundant discharge of inflammatory sinus exudates through the nose and subsequent decongestion lasting approximately $30 \mathrm{~min}^{31}$. Saponins also possess a direct osmotic effect and are able to stimulate mucociliary clearance by triggering mucus secretion ${ }^{32}$. Our previous study has shown that $C E$ application increases microcirculation in the nasal mucosa and dilates blood vessels supplying the mucus glands ${ }^{33} 34$.
Two recent randomised, double-blind, placebo-controlled trials, conducted in Europe ${ }^{27}$ and the US ${ }^{28}$, reported the improvement by $C E$ of facial pain, endoscopic signs (middle meatus mucosal oedema and secretion), reduction of sinus opacification and increase of both investigator and patient treatment satisfaction in patients with ARS. These two studies with level of evidence Ib have confirmed $C E$ is a suitable therapeutic option for ARS recommended by international guidelines $\left(\mathrm{EP}_{3} \mathrm{OS} 2012\right)^{7}$. Few non-controlled, non-blinded studies have reported on the efficacy of $C E$ in larger cohorts of patients with both ARS and CRS. When added to antibiotic treatment, $C E$ therapy caused an increased reduction of ARS symptoms in adults compared to antibiotic alone ${ }^{32} 35$.

Our real-life observational study is the first to show that $C E$ alone or in combination with an oral antibiotic is significantly more effective in treating AECR than antibiotics alone in terms of relieving nasal symptoms (TNSS, nasal congestion, nasal discharge, and facial pain/pressure) as well as decreasing middle meatus mucosal oedema.

Furthermore, the combination of a course of oral antibiotic and $C E$ showed the best results in terms of prevention of CRS recurrence after 6 months of follow-up. The number of AE$\mathrm{CR}$ was 4 times less than in patients receiving oral antibiotic or $C E$ in monotherapy. In addition, an increased number of AECR where physicians replaced a first-line antibiotic with a different one or used alternative treatment options due to insufficient efficacy of initial therapy was mainly observed in group 3 (antibiotic in monotherapy). These findings are in line with the results of previous observational study, which showed that adding $C E$ to oral antibiotic increased the ARS success rate by $15 \%$ as well as $C E$ on top of the combination of oral antibiotic plus topical corticosteroid, which increased the rate of clinical recovery by $24 \%{ }^{36}$.

Among the limitations of the present study, we may firstly highlight the lack of randomisation since allocation of a patient to the treatment group in this real-life observational investigation was based on the physician's choice. Worse initial TNSS in the group 1, as well as the higher initial middle meatus discharge score in this group might be explained by the physicians' intention to reserve combined therapy for patients with relatively more severe symptoms. Secondly, blinding was not used for either patients when receiving the treatment protocol and additional therapy or for physicians when grading endoscopic findings. Thirdly, patients were selected from the group of moderate severity probably discarding those with common cold exacerbations (mild) and those with bacterial rhinosinusitis (severe). All these factors could be theoretically a potential bias for both the physicians and patients. Moreover, like ARS, AECR is a self-limited disease and about $90 \%$ of cases improve spontaneously. 
However, a multicentre (16 independent clinical centres around the Russian Federation) observational study was performed among three potential therapeutic protocols in a real-life design whose aim was to evaluate clinical outcomes for 6 weeks after treatment of AECR and recurrences during 6-month follow-up. The relatively short duration of oral antibiotic therapy (7 days) could be also considered a controversial issue in the study. Although longer courses are used to treat AECR in Western Europe and the US ${ }^{7}$, the design of the study tried, however, to follow the recommendations endorsed in the Russian Federation, where one-week course of antibiotic therapy is recommended for treatment of ARS and AECR ${ }^{37}$.

\section{Conclusions}

The results of this observational study suggest that in AECR of moderate severity, both $C E$ in monotherapy or added to oral antibiotics induces an increased symptom relief and prevents long-term CRS recurrences compared to antibiotics in monotherapy. Thus, intranasal $C E$ may be considered as an alternative to standard antibiotic therapy in the treatment of non-complicated non-severe AECR and potentially help to reduce costs of disease ${ }^{36}$ as well as to reduce antibiotic abuse and the consequent increase in antibiotic resistance.

\section{Acknowledgments}

The study was partially sponsored by INVAR pharmaceutical company.

\section{References}

1 Bhattacharyya N. Chronic rhinosinusitis: is the nose really involved? Am J Rhinol 2001;15:169-73.

2 Benninger MS, Ferguson BJ, Hadley JA, et al. Adult chronic rhinosinusitis: definitions, diagnosis, epidemiology, and pathophysiology. Otolaryngol Head Neck Surg 2003;129:1-32.

3 Meltzer EO, Hamilos DL, Hadley JA, et al. Rhinosinusitis: establishing definitions for clinical research and patient care. Otolaryngol Head Neck Surg 2004;131:1-62.

4 Anand VK. Epidemiology and economic impact of rhinosinusitis. Ann Otol Rhinol Laryngol 2004;193:3-5.

5 Lund VJ. Impact of chronic rhinosinusitis on quality of life and health care expenditure. Clin Allergy Immunol 2007;20:15-24.

6 Alobid I, Guilemany JM, Mullol J. The impact of chronic rhinosinusitis and nasal polyposis on quality of life. Front Biosci 2009;1:269-76.

7 Fokkens WJ, Lund VJ, Mullol J, et al. European Position Paper on Rhinosinusitis and Nasal Polyps 2012. Rhinol Suppl 2012;Mar 23:1-298.
8 Chen Y, Dales R, Lin M. The epidemiology of chronic rhinosinusitis in Canadians. Laryngoscope 2003;113:1199-205.

9 Gordts F, Clement PAR, Buisseret T. Prevalence of sinusitis signs in a non-ENT population. Otorhinolaryngology 1996;58:315-9.

10 Ahsan SF, Jumans S, Nunez DA. Chronic rhinosinusitis: a comparative study of disease occurrence in North of Scotland and Southern Caribbean otolaryngology outpatient clinics over a two month period. Scott Med J 2004;49:130-3.

11 Hastan D, Fokkens WJ, Bachert C, et al. Chronic rhinosinusitis in Europe - an underestimated disease. A $G A^{2} L E N$ study. Allergy 2011;66:1216-23.

12 Kaliner MA, Osguthorpe JD, Fireman P, et al. Sinusitis: Bench to bedside. Current findings, future directions. J Allergy Clin Immunol 1997;99:829-48.

13 Rank MA, Wollan P, Kita H, et al. Acute exacerbations of chronic rhinosinusitis occur in a distinct seasonal pattern. $\mathrm{J}$ Allergy Clin Immunol 2010;126:168-9.

14 Brook I. Bacteriology of chronic sinusitis and acute exacerbation of chronic sinusitis. Arch Otolaryngol Head Neck Surg. 2006;132:1099-101.

15 Brook I. The role of bacteria in chronic rhinosinusitis. Otolaryngol Clin North Am 2005;38:1171-92.

16 Busaba NY, Siegel NS, Salman SD. Microbiology of chronic ethmoid sinusitis: Is this a bacterial illness? Am J Otolaryngol 2004;25:379-84.

17 Kern RC, Conley DB, Walsh W, et al. Perspectives on the etiology of chronic rhinosinusitis: an immune barrier hypothesis. Am J Rhinol 2008;22:549-59.

18 Soler ZM, Oyer SL, Kern RC, et al. Antimicrobials and chronic rhinosinusitis with or without polyposis in adults: an evidenced-based review with recommendations. Int Forum Allergy Rhinol 2013;3:31-47.

19 Boase S, Foreman A, Cleland E, et al. The microbiome of chronic rhinosinusitis: culture, molecular diagnostics and biofilm detection. BMC Infect Dis 2013;13:210.

20 Merkley MA, Bice TC, Grier A, et al. The effect of antibiotics on the microbiome in acute exacerbations of chronic rhinosinusitis. Int Forum Allergy Rhinol 2015;5:884-93.

21 Legent F, Bordure P, Beauvillain C, Berche P. A doubleblind comparison of ciprofloxacin and amoxycillin/clavulanic acid in the treatment of chronic sinusitis. Chemotherapy 1994;40:8-15.

22 Namyslowski G, Misiolek M, Czecior E, et al. Comparison of the efficacy and tolerability of amoxycillin/clavulanic acid $875 \mathrm{mg}$ bid with cefuroxime $500 \mathrm{mg}$ b.i.d. in the treatment of chronic and acute exacerbation of chronic sinusitis in adults. J Chemother 2002;14:508-17.

23 Parikh A, Scadding GK, Darby Y, et al. Topical corticosteroids in chronic rhinosinusitis: a randomized, double-blind, placebo-controlled trial using fluticasone propionate aqueous nasal spray. Rhinology 2001;39:75-9.

24 Lund VJ. Evidence-based surgery in chronic rhinosinusitis. Acta Otolaryngol 2001;121:5-9.

25 Pfaar O, Mullol J, Anders C, et al. Cyclamen europaeum nasal spray, a novel phytotherapeutic product for the man- 
agement of acute rhinosinusitis: a randomized double-blind, placebo-controlled trial. Rhinology 2012;50:37-44.

26 Ponikau JU, Hamilos DL, Barreto A, et al. An exploratory trial of Cyclamen europaeum extract for acute rhinosinusitis. Laryngoscope 2012;122:1887-92.

27 Fokkens W, Lund V, Mullol J, and the European Position Paper on Rhinosinusitis and Nasal Polyps group. $\mathrm{EP}_{3} \mathrm{OS} 2007$ : European Position Paper on Rhinosinusitis and Nasal Polyps 2007. A summary for otorhinolaryngologists. Rhinology 2007;45:97-101.

28 Lund VJ, Mackay IS. Staging in rhinosinusitus. Rhinology 1993;31:183-4.

29 Bachert C, Schapowal A, Funk P, et al. Treatment of acute rhinosinusitis with the preparation from Pelargonium sidoides EPs 7630: a randomized, double-blind, placebo-controlled trial. Rhinology 2009;47:51-8.

30 Federspil P, Wulkow R, Zimmermann T. Effects of standardized Myrtol in therapy of acute sinusitis - results of a doubleblind, randomized multicenter study compared with placebo [in German]. Laryngorhinootologie 1997;76:23-7.

31 Gedevanishvili MD, Gogitidze NM, Sigharulidze IS. Reflex mechanisms of nasoparanasal secretion in the administration of Sinuforte [in Russian]. Vestn Otorinolaringol 2007;(3):541 se.

32 Kryukov AI, Kunelskaya NL, Turovsky AB, et al. New perspectives in non-invasive treatment of sinusitis [in Russian]. Vestn Otorinolaringol 2007;2:33-7.

33 Lopatin AS, Shempelev OA. Influence of Sinuforte on nasal mucosa microcirculation [in Russian]. J Russian Rhinol 2007;4:26-8.

34 Piskunov SZ, Dolzhikov AA, Kalinkin AA. Quantitative histological and histochemical study of the reaction of the nasal cavity and maxillary sinus glands to contact with Sinuforte [in Russian]. J Russian Rhinol 2009;1:17-22.

35 Rybak AA, Rybak AA, Matveeva TV, et al. Effects of Sinuforte on quality of life in rhinosinusitis patients [in Russian]. Vestn Otorinolaringol 2008;3:56-8.

36 Mullol J, Crespo C, Carré C, et al. Pharmacoeconomics of Cyclamen europaeum in the management of acute rhinosinusitis. Laryngoscope 2013;123:2620-5.

37 Angotoeva IB, Lopatin AS, Ekimenko YB. How we treat acute rhinosinusitis in Russia? [in Russian]. J Russian Rhinol 2007;1:23-6.

Received: July 8, 2016 - Accepted: January 15, 2017

Address for correspondence: Andrey Lopatin, Policlinic N. 1, Medical Department, Business Administration of the President of Russian Federation. Sivtsev Vrazhek lane 26/28, 119002 Moscow, Russia. E-mail: lopatin.andrey@inbox.ru 